\title{
Realization of Colpitts Oscillator using second generation current controlled current conveyor
}

\author{
Manoj Joshi \\ Department of Electronics and Communication Engineering \\ SGI Samalkha, Haryana \\ India \\ manojjoshi1506@gmail.com
}

Vivek Bhatt

Department of Electronics and Communication Engineering Insitute of Technology, Gopeswar Uttarakhadnd India

vivekbhatt1587@gmail.com

\begin{abstract}
An inductor-less tunable Colpitts oscillator using second generation current controlled current conveyor (CCCII) is implemented. The circuit uses a CCCII and three grounded capacitors. The passive inductor has been replaced by an active inductor $[14]$ connected to the ground. Thus the absence of external resistor and an inductor in the circuit makes it more complacent for IC Design. The frequency of oscillation can easily be electronically adjusted. The PSPICE simulation results have been deduced. The theoretical results are verified with the parameters of BJT PR100N (PNP) and NR100N (NPN) using PSPICE simulation tool.
\end{abstract}

Index Terms - Inductor-less tunable, Colpitts oscillator, active inductor, CCCII

\section{INTRODUCTION}

An oscillator circuit is an electronic circuit that produces signal of repetitive oscillations, often a sine wave or a square wave [1] . Over the last three decades or so various schemes of the design of the R-C oscillator, based on various current conveyors have been developed [2-4]. The generation of oscillation was invented by Edwin Henry Colpitt's (18721949) [6]. The Colpitts oscillator is mostly designed for generation of high frequency oscillations. The Colpitts oscillator is the exact opposite of the Hartley; instead of using a tapped inductance, Colpitts oscillator uses a tapped capacitor. In 1966 [7] introduces, a new analog building block for high frequency application named as current controlled current conveyor. The most important advantage of current conveyor, compared to the operational amplifier provides high electronic tunablility, wide bandwidth, and low power [8] etc. Colpitts oscillator design is available in various forms like: RF Chaotic Colpitts oscillator [9], BJT transistors based oscillator [10-12], Colpitts oscillator using ICCII [13], complementary Colpitts oscillator in CMOS technology [14].

\author{
Ashish Ranjan \\ Department of Electronics and Communication Engineering \\ National Institute of Technology, Manipur \\ India \\ ashish.ism@rediffmail.com \\ Pramod Benjwal \\ Department of Electronics and Communication Engineering \\ Insitute of Technology, Gopeswar Uttarakhadnd \\ India \\ pramodbe@gmail.com
}

The purpose of presenting work is to analyze and exploit the CCCII based current mode oscillator circuit [2-6] which uses only three CCCIIs and two grounded capacitors. The previously introduced concepts were partly reflected and extended, especially in the following points:

- Inductor has been replaced by the CCCII based Active Inductor [15].

- No resistance and inductor have been used in proposed circuit.

- Minimum number of components (only three capacitors) has been used.

- The frequency of oscillations for active mode inductor-less Colpitts oscillator has been adjusted by bias current I0 and capacitor values individually.

Also a simulation and experimental implementation of the Colpitts oscillator circuits performed using commercially available IC AD844AN.

\section{CIRCUIT DESCRIPTION}

\section{A. Second generation current controlled current conveyor (CCCII)}

Active block CCCII [8] can provide electronic control in various circuits like in filter [16], sinusoidal oscillator [17] etc. The circuit symbol of the CCCII and its trans-linear circuit is shown in Fig.1. Further use $\mathrm{I}_{X}$ and $\mathrm{I}_{Y}$ to denote current and $\mathrm{V}_{\mathrm{X}}$ and $\mathrm{V}_{\mathrm{Y}}$ to denote the voltage at terminal $\mathrm{X}$ and $\mathrm{Y}$, respectively, and $\mathrm{R}_{\mathrm{x}}=\frac{V_{T}}{2 I_{o}}$ to denote intrinsic series input 
resistance of a trans-linear mixed loop (Q1 to $\mathrm{Q} 4)$ at the $\mathrm{X}$ port has electronically tunable via $I_{0}$ and $V_{T}=26 \mathrm{mV}$ is the thermal voltage at room temperature.
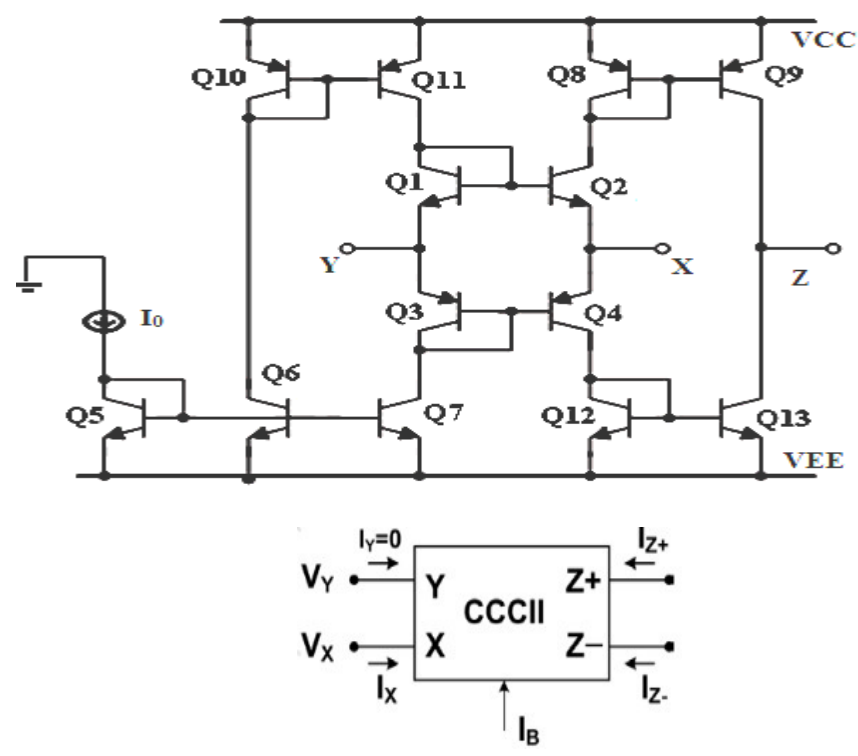

Fig.1. Symbol of CCCII and its trans-linear circuit

The Standard port relationships of CCCII are given below:

$$
\begin{gathered}
I_{Y}=\mathrm{O} \\
V_{X}=V_{Y}+I_{X} R_{X} \\
I_{Z}=I_{X}
\end{gathered}
$$

\section{B. Active Inductor connected to ground [15]}

An inductor based on two current conveyors and a capacitor [15] has been realized.

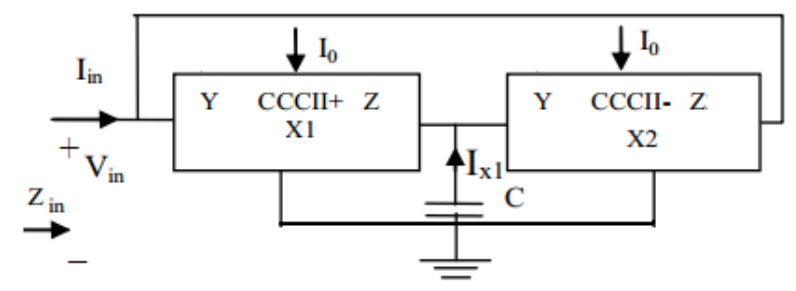

Fig. 2. The realization of an inductor connected to ground [15]

Fig. 2 depicts the realization of inductor design by taking into account the presence of both parasitic resistors $R_{x l}=R_{x 2}=R_{x}$ Here we have considered input impedance which is the ratio of input voltage $V_{i n}$ and input current $I_{i n}$ as given by the equation below:

$$
Z_{\text {in }}=\frac{V_{\text {in }}}{I_{\text {in }}}=s\left(\mathrm{R}_{\mathrm{X}}\right)^{2} \mathrm{C}
$$

Which is equivalent to the standard form of reactive inductance $(s L)$ :

$$
L=\mathrm{R}_{\times 1} \mathrm{R}_{\times 2} \mathrm{C}
$$

\section{Inductor-less Colpitts oscillator circuit and tunable frequency}

The inductor-less active mode Colpitts oscillator has well designed using two grounded capacitors and tunable active mode inductor with analog building block CCCII as the active device shown in Fig.3.

The CCCII based active mode amplifier's X terminal has been connected to the junction of capacitors i.e. series connection of $C_{1}$ and $C_{2}$ (center of the two grounded capacitors) which are placed across a common inductor $\mathrm{L}$ acting as a simple voltage divider. The characteristic equation of active mode inductor less Colpitts oscillator is written as:

$$
s^{2}+\frac{1}{R_{X} C_{1} \mathrm{R}_{\mathrm{x} 2} \mathrm{R}_{\mathrm{x} 3} \mathrm{C}_{3}} s+\frac{C_{1}+C_{2}}{C_{1} C_{2} R_{x 2} R_{x 3} C_{3}}=0
$$

$C_{e q}$ is the equivalent capacitor of $C_{1}$ and $C_{2}$ which are connected in series and is given as.

$$
\frac{1}{C_{e q}}=\frac{1}{C_{1}}+\frac{1}{C_{2}} \text { or } C_{e q}=\frac{C_{1} C_{2}}{C_{1}+C_{2}}
$$

The frequency of oscillations for active mode inductorless Colpitts oscillator is determined by the resonant tunable frequency which is given as:

$$
f_{r}=\frac{1}{2 \pi \sqrt{R_{x 2} R_{x 3} C_{3} C_{e q}}}
$$

Where, $\mathrm{R}_{\mathrm{X} 2}, \mathrm{R}_{\mathrm{X} 3}$ represents the intrinsic resistance of the conveyor at the X terminal of CCCII which is adjustable via $I_{0}$, which gives the tunable active inductance value. If $R_{X 2}=R_{X 3}=$ $R_{X}\left(R_{X}=\frac{V_{T}}{2 I_{o}}\right)$, resonant tunable frequency $f_{r}$ given as:

$$
f_{r}=\frac{1}{2 \pi R_{x} \sqrt{C_{3} C_{e q}}}
$$

Also written as:

$$
f_{r}=\frac{I_{0}}{\pi V_{T} \sqrt{C_{3} C_{e q}}}
$$

Here, (8) show that frequency of oscillations for active mode inductor-less Colpitts oscillator is directly adjusted by bias current $I_{0}$ and grounded capacitances of equivalent capacitor. The concept of grounding of capacitor and absence of passive resistance provides advantage of monolithic IC implementation [18]. This fact is also supported by the Fig.4 which shows the variations of frequency of oscillation w.r.t 
capacitor, when bias current is constant and fixed at $I_{0}=$ $100 \mu \mathrm{A}$, here value of frequencies are decreasing as the capacitor values are increased and further Fig.5 shows the variation of the frequency of oscillation with bias current $\mathrm{I}_{0}$ for two different fixed values of capacitances i.e for $1 \mathrm{pF}$ and $10 \mathrm{pF}$ respectively. Here frequency has been increased by the value of bias current.
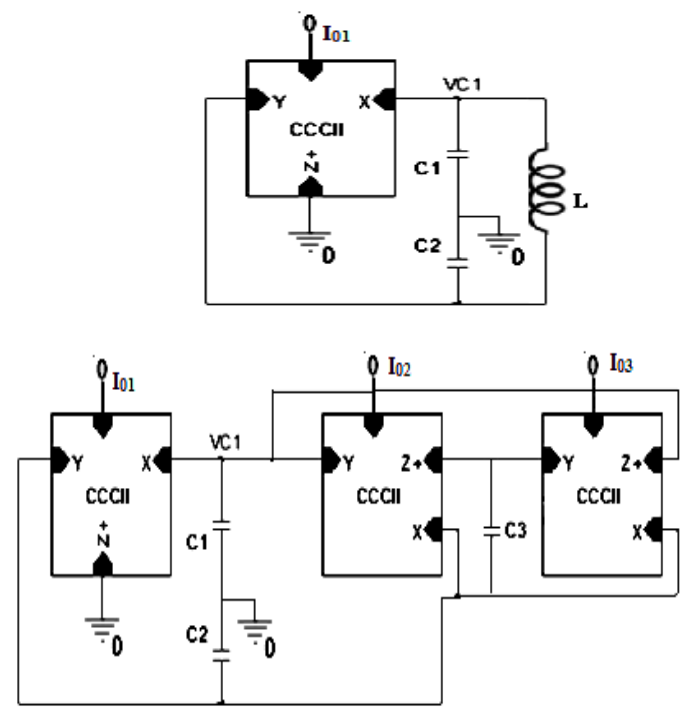

Fig.3.Inductor-less active mode Colpitts oscillator using CCCII

\section{SimUlATION}

The proposed active mode inductor-less Colpitts oscillator circuit is simulated with ORCAD 10.5 in which the circuit is implemented with CCCII using the model parameter [19] with power supply voltages fixed at $V_{s s}=-V_{s s}=2.5 \mathrm{Vdc}$ and bias current $\mathrm{I}_{0}$.

The active mode inductor less Colpitts oscillator circuit has been designed with capacitor values of $C_{1}=C_{2}=C_{3}=5.6$ $\mathrm{nF}$.

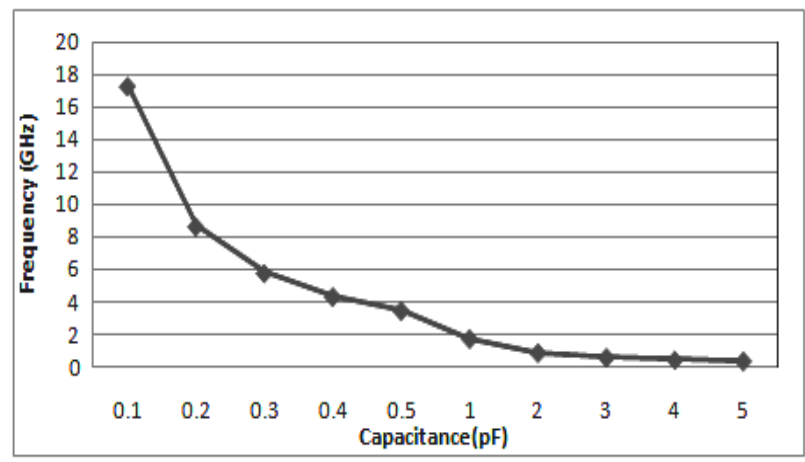

Fig.4. Variations of the frequency of oscillation with capacitor, when bias current is constant $\left(I_{0}=100 \mu \mathrm{A}\right)$

Finally, after simulation, practical realization is performed using AD844AN and three capacitors to confirm theoretical analysis. The DC power supply voltages were taken as $\pm 12 \mathrm{~V}$ and $C 1=C 2=C_{3}=5.6 \mathrm{nF} \pm 5 \%$. The main advantage of the proposed structure is that no resistance is required in the design. The observed frequency of $38.76 \mathrm{MHz}$ is closer to in the simulated value of $40.22 \mathrm{MHz}$. The obtained experimental results in DSO are depicted in Fig.6.

\section{COMPARISON}

The literature survey reveals that a wide variety of circuits have been studied by researchers. In this research work an effort has been made to study and improvement has been achieved. Proposed active mode tunnel diode has several advantages over earlier reported circuits [9-14]. Oscillator circuit has been designed using second generation current controlled current conveyor (CCCII) as active block. The frequency of oscillations for active mode inductor-less Colpitts oscillator has been adjusted by bias current $I_{0}$ and capacitor values individually as shown in fig. 4 and fig.5.Also a practical and experimental implementation of Colpitts oscillator circuit has been performed using commercially available IC AD844AN.

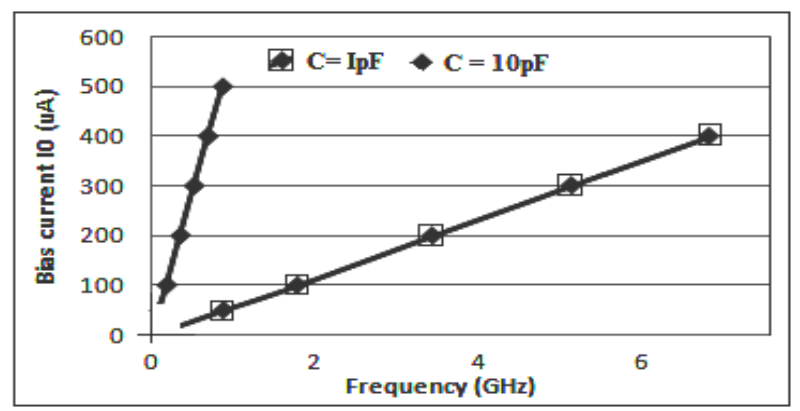

Fig.5. Variations of the frequency of oscillation with bias current $\mathrm{I} 0$ when capacitor values is constant $(1 \mathrm{pF}$ and $10 \mathrm{pF})$

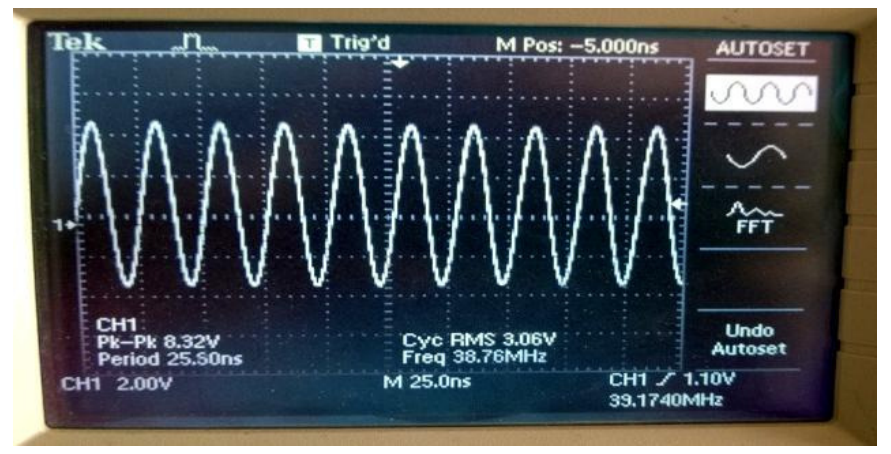

Fig.6. Experimental results: transient response at $38.78 \mathrm{MHz}$

\section{CONCLUSION}

A new active mode inductor-less tunable Colpitts oscillator circuit using CCCII (38.78 MHz) was proposed with apart from offering almost all the advantage like less number of hardware only capacitor are used no inductor and resistor is used for simulation which is the best for IC fabrication. The proposed approach is verified through PSPICE simulations and commercially available IC AD844AN.

\section{REFERENCES}


[1] D. Chattopadhyay, Electronics- fundamentals and applications. New age international, pp. 224-226.

[2] J.W. Horng, "A sinusoidal oscillator using current controlled current conveyors,” Int. J. Electronics, vol. 88, pp. 659-664, 2001.

[3] A. Khan, K. Dey and S. S. Roy,"Novel RC sinusoidal oscillator using second generation current conveyor,"IEEE transaction on instrumentation and measurement, vol. 54, pp. 2402 - 2406, 2005.

[4] A. Lahiri,"Deriving (MO) (I) CCCII Based Second-order Sinusoidal Oscillators with Non-interactive Tuning Laws using State Variable Method," Radioengineering, vol. 20, no. 1, pp. 349-353, 2011.

[5] M. Kumar,"A low power voltage controlled oscillator design.” ISRN Electronics, 2013.

[6] US 1624537, E.H. Colpitts “Oscillation generator,"Published 1: February 1918, issued 12 April 1927.

[7] A. Fabre, O. Saaid, and C. Boucheron, "High frequency applications based on a new current controlled conveyor,"IEEE Transactions Circuits Systems I: Fundamental Theory and Applications, vol. 43, pp. 82-91, Jan. 1996.

[8] C. Toumazou, G. Haigh, Analogue IC design: the current-mode approach. IEE circuit and system series, ISBN-13: 978-0863412158, Peter Peregrinus Ltd. 1990.

[9] M.P. Kennedy, C. Wegener,"RF Chaotic Colpitt's oscillator," In Proceedings of the $3^{\text {rd }}$ NDES. Dublin, Ireland, pp. 255-259, 1995.

[10] M.P. Kennedy, “Chaos in the Colpitts oscillator,” IEEE Trans on Circuits and Systems I: Fundamental Theory and Applications,vol. 41, pp. 771774,1994 .
[11] M.P. Kennedy, G. Maggio,"Nonlinear Analysis of the Colpitts Oscillator and Applications to Design," IEEE TransactionsCircuits and Systems-I: Fundamental Theory and Application,vol. 46, pp. 1118-1130, 1999.

[12] T. jiang, Z.G. Shi,“Ambiguity Function of Chaotic Radar with Colpitts Oscillator,” In Proceedings of PIERS, pp.94-98 2008.

[13] H. Kuntmanand, A. Toker, "New oscillator topologies on a single inverting second generation current conveyor," Turk J ElecEngin, vol.10, pp.110-129, 2002.

[14] C.Y. Cha, S.G. Lee, "A complementary Colpitts oscillator in CMOS technology," IEEE Transactions Microwave Theory Tech, vol.53, pp.881-887, 2005.

[15] T. Ettaghzouti, N. Hassen and K.Bedbes,"High-performance secondgeneration controlled current conveyor CCCII and high frequency applications," International Journal of Electrical, Computer, Energetic, Electronic and Communication Engineering, vol.5, pp.1759-1768, 2011.

[16] N Pandey, S.K. Paul,"Realization of Generalized Mixed Mode Universal Filter Using CCCIIs," Journal of Active and Passive Electronic Devices, vol. 55, no 3, pp.279-293, 2009.

[17] A. Ranjan, M. Ghosh and S.K. Paul,"Current Conveyor Based CMOS Sinusoidal Oscillator," Journal of Active and Passive Electronic Devices, vol. 7, pp. 173-179, 2012.

[18] M. Bhusan, R.W. Newcomb, "Grounding of capacitors in integrated circuits," Electronics Letters, vol. 3, pp.148-2, 1967.

[19] R. Frey, "Log domain filtering: 'An approach to current-mode filtering," IEE Proceeding G (circuit Devices and system), pp. 406-10, 1993. 